\title{
Conjoint utility analysis of technical maturity and project progress of construction project
}

\author{
Wei $\mathrm{MA}^{1}$, \\ ${ }^{1}$ Department of economics and management from Tianjin university of science and technology, Dagu South Road No. 1038, Hexi \\ District, Tianjin, China
}

\begin{abstract}
In this paper, taking construction project as the research object, the relationship between the project maturity index calculated by the construction project technical risks with different fine degree and the project progress index is studied, and the equilibrium relationship between the Party A's utility curve and the Party B's cost curve of using project maturity index and project progress index as the research variables is analyzed. The results show that, when the construction project technical risk division is more precise, the conjoint utility of the project's technical maturity index and the project progress is higher, and the project's Party A and Party B two sides are closer to the optimal equilibrium. This shows that the construction project technical risk must be finely divided, and managed and controlled respectively, which will help to improve the conjoint utility of the project Party A and Party B two sides.
\end{abstract}

\section{Introduction}

The complexity of construction project technology, the diversification of the management and the investment main body, the scale of the project, the multi degeneration of the project implementation environment have resulted in the construction project with the characteristics of large investment, many technical links, high risk, long cycle and so on. [1].These characteristics will cause the construction units to be inevitably faced with the solution of the inherent contradiction between the project technical risk and the duration of the project risk after the construction units have undertaken the construction task of the construction project [2]. This requires that after the signing of the construction contract, the construction side (i.e. construction project Part B) and construction units (i.e. construction project Part A) must refine calculations according to the contract schedule requirements and technical characteristics, try to avoid inherent contradictions between project duration risk and technology risk, and strive to reach the utility balanced state of project Part A and Part B two sides, find the meeting point to take into account the project time limit and technical requirements, strive to achieve the completion of the schedule and even ahead of schedule under the premise of ensuring the quality of construction projects, make the project Part A and Part B both to achieve the goal of maximizing utility. In this paper, the technology maturity is used to measure the technical risk, and the project schedule index is used to scale the project duration risk, and the utility curve and cost curve are used to describe the equilibrium utility analysis of the construction project Part A and Part B both sides.

\section{TECHNICAL MATURITY INDEX}

Domestic and foreign scholars have a different explanation for the concept of technology maturity degree, although there are differences in the expression of various interpretations, in essence, it refers to the estimation of the implementation capacity size of the technology to meet the project expected goal. The evaluation of technical maturity is to measure the stage or state of the results of the technical research and how much to achieve the expected goal of the project [4]. In this paper, the measurement method based on the technical risk of the construction project is adopted to measure the technology maturity, the greater the project technical risk is, the lower the technical maturity level of the project is. In the calculation of technical risks of the construction project, in order to explain the influence of technical risk division level on project technical maturity and project schedule, the construction project technical risk is divided into three levels in this paper. In Figure 1, earthwork engineering construction technology risk is taken as an example to explain the relationship between the three levels of technical risks.

$\overline{{ }^{a} \text { Corresponding author: maweilwtg } @ 126 . c o m ~}$ 
Table 1. Earthwork construction technology risk.

\begin{tabular}{|c|c|c|}
\hline $\begin{array}{l}\text { The first level } \\
\text { technical risk }\end{array}$ & $\begin{array}{l}\text { The second technical } \\
\text { risk }\end{array}$ & $\begin{array}{l}\text { The third } \\
\text { technical risk }\end{array}$ \\
\hline \multirow{11}{*}{$\begin{array}{l}\text { Earthwork } \\
\text { construction } \\
\text { technology risk }\end{array}$} & \multirow[t]{2}{*}{$\begin{array}{l}\text { Supporting structure } \\
\text { construction risk }\end{array}$} & $\begin{array}{l}\text { Sheet pile } \\
\text { engineering } \\
\text { accident }\end{array}$ \\
\hline & & $\begin{array}{c}\text { Fill embankment } \\
\text { slope landslide }\end{array}$ \\
\hline & \multirow{4}{*}{$\begin{array}{l}\text { Environmental risk } \\
\text { caused by foundation } \\
\text { pit dewatering }\end{array}$} & Site water \\
\hline & & Landslide \\
\hline & & Flow sand \\
\hline & & Piping effect \\
\hline & \multirow{2}{*}{$\begin{array}{l}\text { Unreasonable } \\
\text { foundation pit } \\
\text { reinforcement risk }\end{array}$} & $\begin{array}{c}\text { Foundation pit } \\
\text { backfill soil } \\
\text { subsidence }\end{array}$ \\
\hline & & $\begin{array}{c}\text { Foundation trench } \\
\text { backfill soil } \\
\text { subsidence }\end{array}$ \\
\hline & \multirow[t]{3}{*}{$\begin{array}{l}\text { Foundation pit } \\
\text { excavation risk }\end{array}$} & $\begin{array}{c}\text { Excavation } \\
\text { embankment } \\
\text { slope landslide } \\
\end{array}$ \\
\hline & & $\begin{array}{l}\text { Foundation pit } \\
\text { soaking }\end{array}$ \\
\hline & & $\begin{array}{l}\text { Foundation trench } \\
\text { soaking }\end{array}$ \\
\hline
\end{tabular}

In this paper, take a construction project example as the research object, and invite 18 industry experts to estimate and summarize the occurrence probability and influence degree of various level technical risk factors of the project. Calculate the weighted average number of each level technical risk to obtain that the first technical risk, the second level technical risk and the third technical risk of the project are 52.98, 112.41 and 581.76 separately. According to the construction project practical experience, experts give that the first level technical risk standard number of this general type project is 120 , the second level technical risk standard number is 200 , the third level technical risk standard number is 850 . This paper defines that each level technology mature degree index = technical risk standard number / the project technical risk number, which is concluded that the technology maturity index divided by the first level technology risk is 2.27 , the technical maturity index divided by the second level technology risk is 1.78 , and the technical maturity index divided by the third level technology risk is 1.46.

\section{Utility curve and cost curve}

Project technical maturity index reflects the technical level of a construction project, and another important factor affecting the cost and quality of construction projects is the project progress, which reflects the comprehensive management level of the project. The project progress considered in this paper excludes the influence of technical risk factors, and the technical risk factors are reflected in the technical maturity index. The conjoint utility curve of a construction project is composed of two factors that one is the technical maturity index which reflects the project technical level, and another is the project progress index which reflects the project management level. According to the project practice experience, the industry experts give ten groups data of project schedule and technical risk level, which the project progress indexes are represented by the average number of the ten group project schedule data are divided by each project schedule number, and the project technology maturity indexes use the second level project technology risk classification as the standard, as shown in table 1 . According to these data, the conjoint utility curve of the construction project Party A is fitted, as shown in figure 1 . The $\mathrm{X}$ axis represents the project schedule index, the $\mathrm{Y}$ axis represents the project technical maturity index, and $U$ represents the utility curve of the Party A. Any pair of combination on the utility curve is no difference for Party A.

Table 2. project progress index and technical maturity index.

\begin{tabular}{|c|c|c|c|c|c|c|c|c|c|c|}
\hline & $\operatorname{Pr}$ & $\operatorname{Pr}$ & $\operatorname{Pr}$ & $\operatorname{Pr}$ & $\operatorname{Pr}$ & $\operatorname{Pr}$ & $\operatorname{Pr}$ & $\operatorname{Pr}$ & $\operatorname{Pr}$ & $\operatorname{Pr}$. \\
.1 & .2 & .3 & .4 & .5 & .6 & .7 & .8 & .9 & 10 \\
\hline $\begin{array}{c}\text { progr } \\
\text { ess } \\
\text { index }\end{array}$ & 1. & 1. & 1. & 1. & 0. & 0. & 0. & 1. & 0. & 0.6 \\
\hline $\begin{array}{c}\text { techn } \\
\text { ical } \\
\text { matu } \\
\text { rity } \\
\text { index }\end{array}$ & 0. & 0. & 0. & 0. & 1. & 1. & 1. & 0. & 0. & 2.1 \\
& 42 & 91 & 90 & 37 & 00 & 22 & 88 & 65 & 8 \\
\hline
\end{tabular}

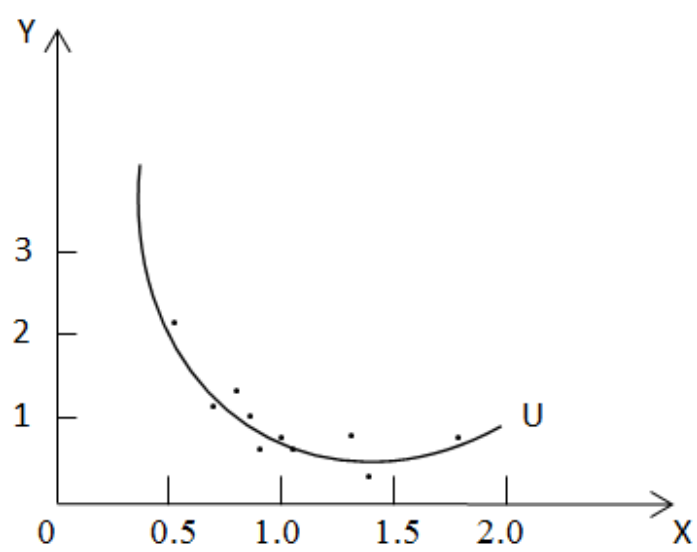

Figure 1. Party A conjoint utility curve.

The Party B's cost curve of the construction project can be represented by the $\mathrm{aX}+\mathrm{bY}+\mu=\mathrm{c}$, where a represents the management cost ratio related to the progress in the project cost, b represents the technology cost ratio related to the technology maturity level in the project cost, $\mu$ represents the other controllable factors in project cost, and c represents the project cost. The Party B's cost curve of the construction project is shown in Figure 2. The slope and intercept of the cost curve are determined by the coefficient $a$, the coefficient $b$, the cost $c$ and $\mu$ together. The triangle area composed by the costs line with the $\mathrm{X}$ axis and $\mathrm{Y}$ axis is the project Part $\mathrm{B}$ acceptable cost budget range, and the outside area is the part that cannot be realized in the project budget under 
the established technical maturity level and progress requirements.

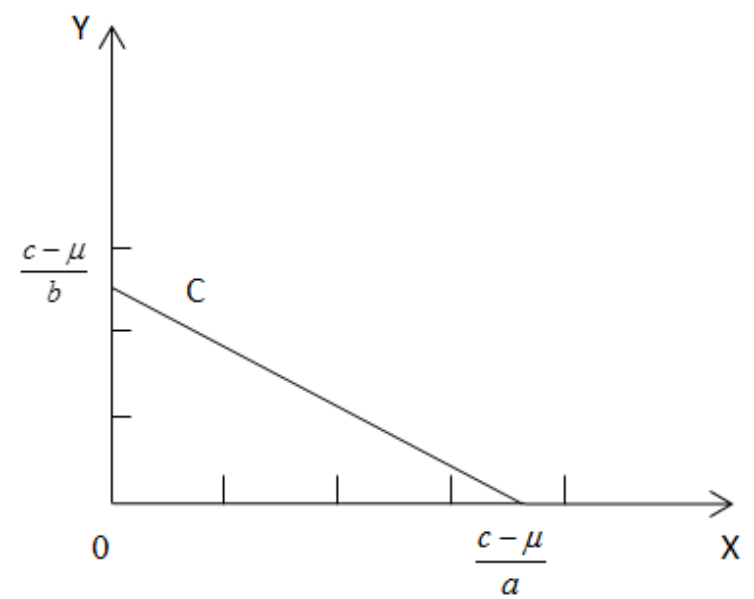

Figure 2. Party B cost curve.

\section{Equilibrium}

The Party A's utility curve indicates that any pair of combination of the technical maturity index and progress index on this curve is no difference to Party A, or it is impossible to be realized that speed up the project progress under the established technical maturity level. The upper right area of the curve indicates that the technology maturity is higher under the same project progress, the project scale is larger under the same technical maturity requirements. On the contrary, the curve of being more close to the origin means that the effectiveness of Party A is smaller.

Party B's cost curve represents the Party B's maximum cost of a construction project, and the slope of the cost curve will change, when the proportion of the cost related to the progress and the technical cost related to technical maturity happens to change. When the project cost is increased, the cost curve moves to the right. The cost curve of being more close to the origin indicates that the project cost is smaller.

In this paper, investigation of the construction project progress index is based on the same method as above. The average number of ten groups of project progress data divided by the project progress number obtains that the project progress index is 1.78 , which is depicted in Part $\mathrm{A}$ and Part $\mathrm{B}$ equilibrium diagram, that is, the $\mathrm{A}$ point in Figure 3. The technical maturity index of the first level technical risk of the project calculated by the above is 2.27 , which is depicted in the equilibrium graph of Part $\mathrm{A}$ and Part $\mathrm{B}$, that is, the $\mathrm{B}$ point in Figure 3. The technical maturity index of the second level technology risk is 1.78 , that is, the $\mathrm{C}$ point in figure 4 . The technical maturity index of the third levels technical risk is 1.46, that is, the $\mathrm{D}$ point in figure 3 .

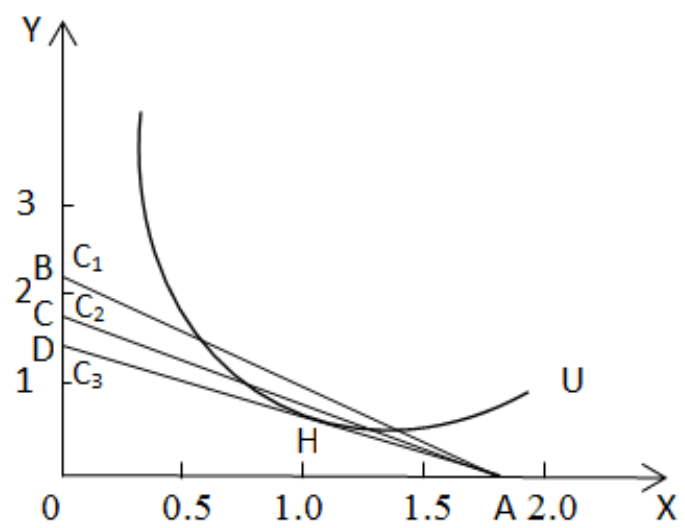

Figure 3. Part A and Part $B$ two sides balance chart

In Figure 3 drawn according to the actual situation of the construction project, it can be seen that Party B cost curve $A D$ and Party A utility curve $\mathrm{U}$ are tangent to the $\mathrm{H}$ point, $\mathrm{AB}$ and $\mathrm{AC}$ lines Intersect with utility curve $\mathrm{U}$. It shows that in the case of the known Party A utility curve, the cost curve which is composed by the technical maturity index obtained according to the three level technology risk division and the utility curve of Party B can reach the optimal equilibrium state. The cost curve which is composed by the technology maturity index obtained according to the first level technical risk and the second level technology risk division and the Part B utility curve does not reach the optimal equilibrium. This shows that there is a better combination to make Part A and Part B two sides to achieve a balanced state. It is shown in figure 4 .

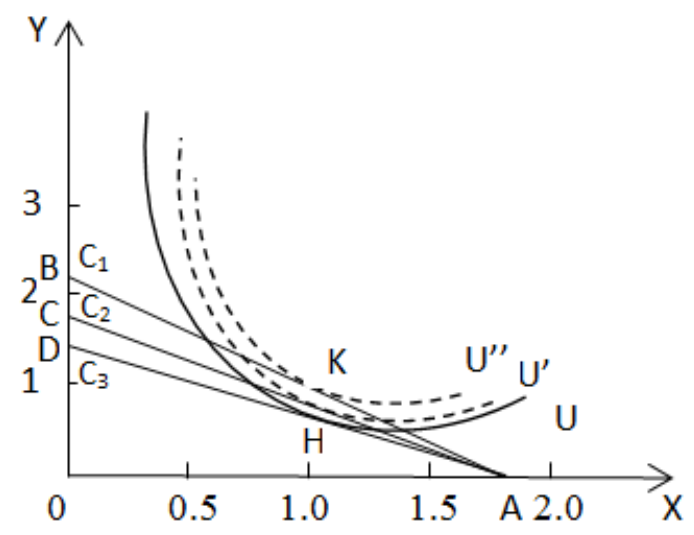

Figure 4. Adjustment of optimal equilibrium

In Figure 4, it can be seen that there are more efficient curves $U$ 'and $U$ " whose tangent lines are the cost lines $\mathrm{AB}$ and $\mathrm{AC}$. On the cost curve $\mathrm{AB}$ which is composed by the technology maturity index obtained according to the first level technical risk division, when moves to the upper left corner from point A along the cost curve, it can be found that higher utility curve $U$ 'and $A B$ is tangent to the point $K$. The utility of $U$ " curve is higher than $U$ 'curve and higher than U curve, but it cannot be achieved under current project condition.

Because under the same technical level requirements, the $\mathrm{U}$ 'and $\mathrm{U}$ ' utility curve require the project to have a larger scale, or under the same project scale, require a higher technical maturity level. All these are impossible to 
achieve under the premise of given the scale of the construction project, the construction period and the cost budget.

In the construction project of this paper research, there are only a set of optimal combination of the cost curve and the utility curve, that is, the cost curve AD of Party B and the utility curve $U$ of Party A. This just shows that when the technology maturity index is measured according to the three levels of technology risk division, the combination of Part B's cost curve and Part A's utility curve of the project is the most economical and efficient. When the technology maturity index is measured according to the first level technology risk and the second level technology risk, due to the risk division being not precise enough, the measured technical maturity index is not accurate enough to reflect the actual technical level of the project, so that the combination with the progress index to describe the effectiveness of Party A and the cost of Party B cannot reach the optimal equilibrium state, resulting in the loss of economic efficiency. Under the premise of the measuring as accurately as possible of the project technology maturity, this paper tries to find the balance point between the technical maturity and the progress of the construction project through the utility curve and cost curve, and furtherly explain the intrinsic relationship between the technical risk and the progress time out.

\section{Conclusion}

In this paper, the relationship between the project maturity index calculated by the construction project technical risks with different fine degree and the project progress index is studied, and taking the concrete construction project as the research object, the equilibrium relationship between the Party A's utility curve and the Party B's cost curve of using project maturity index and project progress index as the research variables is analyzed. The results show that when the project technical risk is divided into the most precise three levels, the utility curve of the project Party A and the cost curve of the project Party B presents a balanced state. This indicates that when the construction project technical risk division is more precise, the measure of the project's technical maturity index is more accurate, and the project Party A and Party B two sides are closer to the optimal equilibrium which makes Party A's utility as high as possible while also making Party B's cost close to the minimum. This also explains the intrinsic relationship between technical risk and progress time out in a construction project from a new perspective, in order to provide a new solution for the future research on the technical risk and progress of the construction project.

\section{References}

[1]Forecasting Analysis and Control Measures of Risk Cost of Construction Project. Chinese and Overseas Architecture, 08(2009)
[2]Analysis on cost risk and cost control measures of construction project. City Architecture,15(2015)

[3]A Study of Influence of Technology Readiness Level on Spacecraft Development Schedule. Aerospace industry management , 18(2009)

[4]Research on the relationship between technology maturity and risk management. Aeronautic Standardization and Quality, 3 (2012) 